\title{
Reply to Comment to: A simplified surgical technique for recurrent inguinal hernia repair following total extraperitoneal patch plastic. Balta AZ, Senol Z, Sucullo I
}

\author{
P. Knyazeva ${ }^{1}$ P. F. Alesina ${ }^{1} \cdot$ M. K. Walz ${ }^{1}$
}

Received: 21 October 2017 / Accepted: 9 December 2017 / Published online: 8 January 2018

○) Springer-Verlag France SAS, part of Springer Nature 2018

Dear Sir,

With great interest we read the comments of Dr. Balta and coauthors on our paper "A simplified surgical technique for recurrent inguinal hernia repair following total extraperitoneal patch plastic" and are thankful for their hints for improvement.

In 31 of 35 cases the initial TEP procedure was performed by us. Twenty of these 31 patients had lateral, 11 medial inguinal hernias. For TEP we place three ports in the midline. A $10-\mathrm{mm}$ port was inserted through a subumbilical incision and used for the camera ( $10 \mathrm{~mm}-30^{\circ}$-endoscope). $\mathrm{CO}_{2}$ was inflated with a pressure of $12 \mathrm{mmHg}$. The working space was created by blunt dissection using the tip of the camera; a dilating balloon was not used. The two working trocars were inserted about $5 \mathrm{~cm}$ above the pubic bone (10 $\mathrm{mm}$ port) and a 5 -mm port between the two initial incisions. In medial hernias the sac was pushed cranially; in lateral hernias it was dissected from the spermatic cord. We always (since 2003) used the same type of non-resorbable heavyweight mesh (Parietex, Medtronic ${ }^{\circledR}$ ). The mesh was not fixed. A suction drainage was used in all cases and removed on the first postoperative day.

The majority $(72 \%)$ of the recurrent hernias were lateral causing an abdominal wall weakness almost always at the lower edge of the implanted mesh. In these cases the hernia sac was resected (not in medial hernias) as in conventional open hernioplasty. Of course, we could not identify the reasons for recurrence in our series. Shrinkage-as commented

This reply refers to the article available at https://doi.org/10.1007/ s10029-017-1709-5.

\section{P. Knyazeva}

polinakn@gmail.com

1 Department of Surgery and Centre of Minimally Invasive Surgery, Kliniken Essen-Mitte, Essen, Germany by Dr. Balta—seems to be an option. Early dislocation may be another reason. Nevertheless, recurrence after TEP is rare and was just $2 \%$ compared to our primary cases.

In the first cases of our new simplified method, we planned a Shouldice operation or a Lichtenstein procedure. We were surprised that we could identify the lower edge of the mesh and could fixate it to the inguinal ligament closing a defect of $1-2 \mathrm{~cm}$. This is indeed "simplified" compared to previously mentioned alternative techniques. We strongly recommend the use of that new surgical technique in recurrent inguinal hernias after TEP as it combines the advantages of the anterior and the posterior approach. We could successfully use this method in 35 of 54 cases (65\%). The latter information was deleted during the review process.

In addition, from our point of view, TEP is not a laparoscopic but an extraperitoneal technique. "Laparoscopy" per se means taking a look into the abdominal cavity. That should not happen in TEP.

\section{Compliance with ethical standards}

Conflict of interest Polina Knyazeva, Martin K. Walz, Piero F. Alesina declare that they have no conflict of interest.

Ethical approval All procedures followed were in accordance with the ethical standards of the responsible committee on human experimentation (institutional and national) and with the Helsinki Declaration of 1975 , as revised in 2000 .

Human and animal rights All procedures performed in studies involving human participants were in accordance with the ethical standards of the institutional research committee and with the 1964 Helsinki declaration and its later amendments or comparable ethical standards.

Informed consent Informed consent was obtained from all individual participants included in the study. 